\title{
An FEA approach to simulate disc brake wear and airborne particle emissions
}

\author{
Gabriele Riva $^{\mathrm{a}, *}$, Giorgio Valota ${ }^{\mathrm{a}}$, Guido Perricone ${ }^{\mathrm{a}}$, Jens Wahlström ${ }^{\mathrm{b}}$

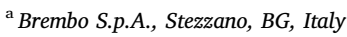 \\ ${ }^{\mathrm{b}}$ KTH Royal Institute of Technology, Stockholm, Sweden
}

\section{A R T I C L E I N F O}

\section{Keywords:}

Disc brakes

\section{Emission}

Simulation

Wear

\begin{abstract}
A B S T R A C T
Emissions from disc brake wear adversely affect the air quality in cities. Finite Element Analysis (FEA) approaches focussing on the macroscopic wear of pads and rotors can be found in the literature, but none of these take the wear and emission dependence of the local contact pressure and sliding speed into account. The aim of the present study is to further develop an FEA approach for simulation of macroscopic wear and airborne emission to include the dependences of local contact pressure and sliding speed by implementing wear and emission maps obtained by pin-on-disc tribometer tests. Results from a dyno bench test are compared with simulated results. The simulated rotor and pads wear, and airborne emissions are in line with the measured values.
\end{abstract}

\section{Introduction}

Non-exhaust airborne particle emissions are a problem for the air quality in cities and it can affect human health ([1-3]). Most of the studies in this field have been focused on engine emissions. Recently, it has been showed that the non-exhaust emissions from road vehicles are as important as the engine emissions for PM10 [4,5]. Brake systems are one of the main sources of non-exhaust emissions. During braking, the rotor slides against the pads and the contact surfaces wear. Some of the wear debris become airborne, some falls to the ground, and some gets stuck on surfaces in the environment.

The wear and airborne emissions from disc brakes strongly depend on the contact pressure, temperature, and sliding speed distribution in the contact interface between the pads and rotor (e.g. Refs. [6-12]). In turn, the wear affects the surface geometries of both the pads and rotor and therefore the contact pressure and temperature distributions. It is hard to study the contact during braking $([13,14])$ and therefore different simulation approaches focussing on contact pressure, contact temperature, and wear have been developed by different authors in the past ([15-17]). The overall aim with these kinds of simulation approaches is to explain what is happening in the pad-to-rotor interface during braking and to predict wear and temperature. Few studies can be found in the literature $([18,19])$ which focus on simulation of airborne particle emissions.

Contact simulations can be done on different size scales depending on the phenomena to be studied. A mesoscopic size scale is needed to simulate the creation and destruction of contact plateaus/patches ([20-23]) while a macroscopic size scale could be enough to simulate the macroscopic wear and airborne particle emission from the pads and rotor.

FEA can be used to better understand the contact behaviour on a macroscopic size scale. Abubakar et al. [24] used an FEA to compute the contact pressure between rotor and pads, and they compared the results with experimental tests. Han et al. [25] performed a thermomechanical analysis to study the effect of a non-uniform contact pressure distribution on wear. They also developed a pad shape optimization in order to have a more uniform contact pressure distribution. Infrared thermal images of the rotor can be used to calibrate Finite Element Analysis (FEA) contact simulations [26]. Schmidt et al. [27] developed a 3D transient non-linear FEA to predict the wear on a tilted shaft-bushing bearing. Sun et al. [28] proposed a model to investigate the rail non-uniform wear evolution combining the vehicle dynamic, the Kalker's variational method and Sheffield University material wear model. Söderberg et al. [16] and Valota et al. [17] developed an FEA approach to compute the pressure distribution on the contact interface. From the pressure distribution, knowing the sliding velocity, a generalized Archard's wear law and Euler's integration scheme were used to simulate the wear. Wahlström et al. [18] further developed this approach to include airborne particle emission. None of the studies consider the wear and emission dependence of differences in the local

\footnotetext{
* Corresponding author.

E-mail address: Gabriele_Riva@brembo.it (G. Riva).
} 


\author{
Abbreviation \\ ALE Arbitrary Lagrangian Eulerian adaptive meshing \\ CFD Computational Fluid Dynamics \\ EU European Union \\ FE Finite Element \\ FEA Finite Element Analysis
}

HEPA High Efficiency Particulate Air

LACT Los Angeles City Traffic

LVDT Linear Variable Differential Transformer

PM Particulate Matter

PM10 Particulate matter with an aerodynamic diameter smaller than $10 \mu \mathrm{m}$ contact pressure and sliding speed. The studies considered drag tests with a constant rotational velocity or repeated brake events with the same braking conditions each time. The simulated airborne emissions found in the literature have not been compared with results from dyno bench tests run with a city traffic cycle in order to investigate their validity.

The aim of the present study is to further develop the FEA approach [18] to include the wear and emission dependences of local contact pressure and sliding speed to simulate the macroscopic wear and airborne emissions. This is done by implementing wear and emission $p v$ maps obtained by pin-on-disc tribometer tests [10] in the FEA approach. In order to investigate the validity of the approach a simulation is run with the same running conditions as a dyno bench test.

\section{Simulation methodology}

The methodology presented by Wahlström et al. [18] is further developed in the present work to include wear and emission $p v$-maps. To summarize, first the specific wear rate and particle rate are mapped with respect to different contact pressures $(p)$ and sliding speeds $(v)$ by experiments conducted in a pin-on-disc tribometer on material level [10]. These maps are then used as input to an FEA on component level. To investigate the validity of the simulation methodology, the simulated pads and rotor wear, and airborne particle emission are compared to experimental measurements in a dyno bench designed for particle emission studies [11]. An overview of the simulation methodology and its validation procedure is presented in Fig. 1. Each step of the simulation methodology is explained in the following sections.

\section{Brake system and driving condition}

The brake system studied is described in subsection 2.1 and the driving conditions in subsection 2.2.

\subsection{Brake system}

A left front disc brake system of a typical medium-sized car is used in this study (see Fig. 2). Important data for the reference car and brake system is presented in Table 1 . This disc brake consists of a sliding calliper, two low-metallic pads, and a ventilated grey cast-iron rotor. The elemental composition measured using X-ray fluorescence spectrometry of the pad friction material and the rotor is shown in Table 2. The densities of the friction material and the rotor are 2.75 and $7.1 \mathrm{~g} /$ $\mathrm{cm}^{3}$, respectively.

\subsection{Driving conditions}

Grigoratos et al. [29] presented a summary of driving cycles commonly used by the industry in order to investigate the friction and wear performance of brakes. The Los Angeles City traffic cycle (LACT [30]) can be used to study urban driving conditions with inertia dyno benches. The median (50\%) and extreme (95\%) values for initial vehicle speed before deceleration, vehicle speed after deceleration, deceleration time, and deceleration according to Grigoratos et al. [29] are summarised in Table 3.

The LACT is a time-driven cycle which means that each deceleration (braking) starts at a certain time regardless of the temperature of the brake system. It is know that the generation of airborne particle emission from brakes strongly depends on the temperature of the pads and rotor $([8,10,12])$. The initial temperature will differ for different inertia dyno benches due to different designs of cooling systems. A cycle that is driven by the initial temperature of the rotor is preferable to produce repeatable results in different dyno bench test setups. Consequently, a reduced temperature-driven LACT, developed by Mathissen and Evans [31], was used in the present work to study airborne brake emissions. The reduced LACT cycle consists of a sub-set (217 decelerations) of the full LACT (3542 decelerations). The median initial velocity and decelerations of the reduced LACT cycle were chosen to be the same as for full LACT cycle. In the reduced LACT, the next deceleration starts when the rotor temperature is below a certain value.

\section{Pin-on-disc tribometer}

The pad and rotor materials described in sub-section 2.1 were tested by Wahlström et al. [10] in a pin-on-disc tribometer at 12 nominal pressure and sliding velocity combinations. The $p v$-maps of specific wear rates and airborne particle mass rates from that investigation are used as input in the present work. The experimental setup and the results are summarised below.

Cylindrical pin specimens with a diameter of $10 \mathrm{~mm}$ were made from pads while the disc specimens with an outer diameter of $60 \mathrm{~mm}$ were made from rotors. Nominal contact pressures between 0.3 and $1.2 \mathrm{MPa}$ and sliding velocities between 1 and $4 \mathrm{~m} / \mathrm{s}$ were tested, which corresponds to calliper pressures of 0.6-2.4 MPa and car speeds from 10 to $40 \mathrm{~km} / \mathrm{h}$ which is in line with the median values of the LACT (Table 3). The displacement $\Delta h$ of the pin holder was measured in realtime with an LVDT (Linear Variable Differential Transformer) sensor

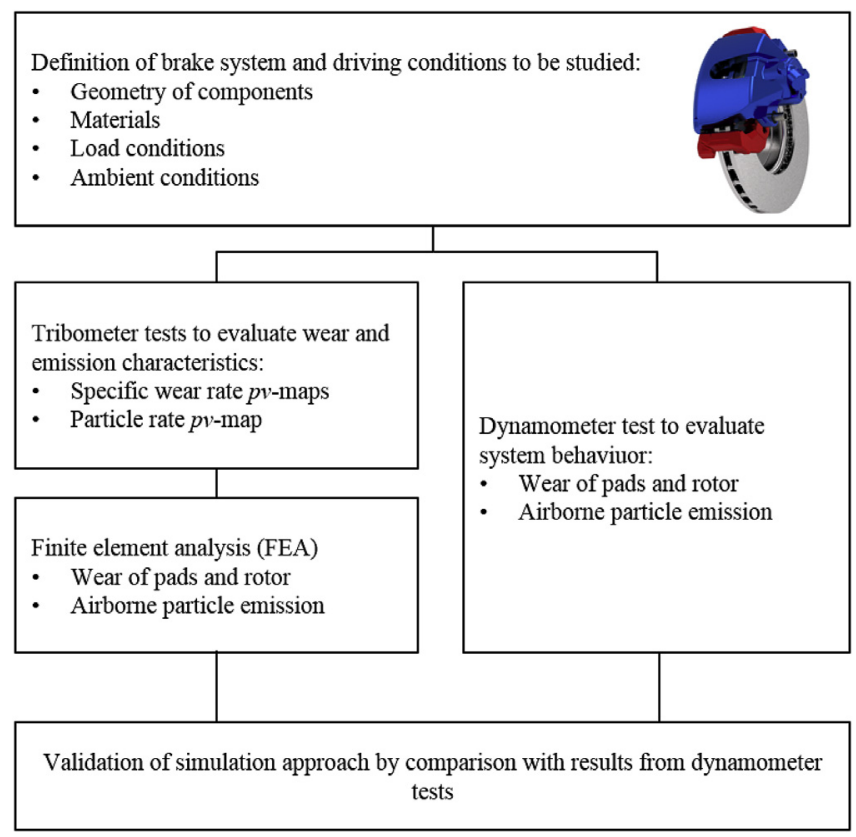

Fig. 1. Proposed simulation methodology. 


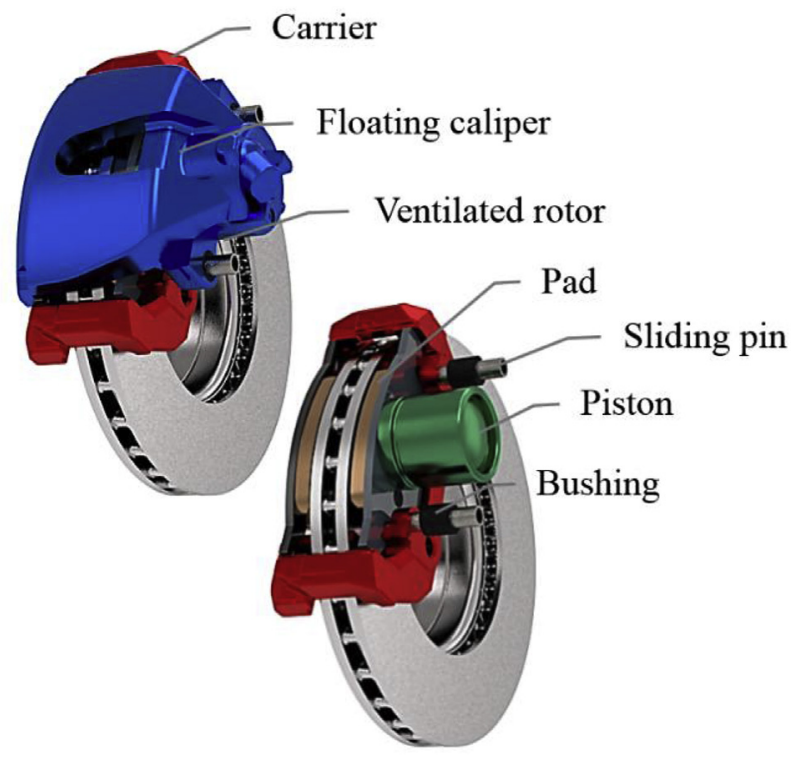

Fig. 2. Single piston sliding calliper disc brake.

Table 1

Data of the car and its front left disc brake.

\begin{tabular}{ll}
\hline Front wheel load & $690 \mathrm{~kg}$ \\
\hline Wheel radius & $314 \mathrm{~mm}$ \\
Rotor outer radius & $139 \mathrm{~mm}$ \\
Rotor inner radius & $80 \mathrm{~mm}$ \\
Rotor effective radius & $113 \mathrm{~mm}$ \\
Pad surface area & $5080 \mathrm{~mm}^{2}$ \\
Cylinder diameter & $57 \mathrm{~mm}$ \\
\hline
\end{tabular}

Table 2

Elemental composition of the pad and disc material as measured by X-ray fluorescence spectrometry.

\begin{tabular}{lll}
\hline Element & Pin [w\%] & Disc [w\%] \\
\hline $\mathrm{C}$ & 39.8 & 3.80 \\
$\mathrm{O}$ & 1.13 & - \\
$\mathrm{Mg}$ & 6.50 & - \\
$\mathrm{Al}$ & 7.11 & - \\
$\mathrm{Si}$ & 3.13 & 1.80 \\
$\mathrm{~S}$ & 2.37 & 0.06 \\
$\mathrm{~K}$ & 1.03 & - \\
$\mathrm{Ca}$ & 0.52 & - \\
$\mathrm{Ti}$ & 0.20 & - \\
$\mathrm{Cr}$ & 2.53 & - \\
$\mathrm{Fe}$ & 16.7 & 93.70 \\
$\mathrm{Cu}$ & 9.12 & - \\
$\mathrm{Zn}$ & 5.57 & - \\
$\mathrm{Mo}$ & 0.21 & - \\
$\mathrm{Sn}$ & 4.08 & - \\
$\mathrm{Mn}$ & - & 0.65 \\
\hline
\end{tabular}

Table 3

Characteristics of the LACT driving cycle.

\begin{tabular}{lll}
\hline Quantity & Median (50\%) & Extreme (95\%) \\
\hline Initial vehicle speed $[\mathrm{km} / \mathrm{h}]$ & 42 & 61 \\
Final vehicle speed $[\mathrm{km} / \mathrm{h}]$ & 7 & 52 \\
Deceleration time $[\mathrm{s}]$ & 3.9 & 12.5 \\
Deceleration $\left[\mathrm{m} / \mathrm{s}^{2}\right]$ & 0.9 & 1.8 \\
\hline
\end{tabular}

(WA/10 HBM GMbH). The specific wear rate can be computed from the Archard's wear law [32]:

$k_{L V D T}=\frac{\Delta h \cdot \pi \cdot r_{p}^{2}}{\Delta s \cdot F_{N}}$

where $r_{\mathrm{p}}$ is the pin radius, $\Delta s$ is the sliding distance during the test, and $F_{\mathrm{N}}$ is the normal load applied to the pin. The mass loss of the disc test specimens was measured by weighing the test samples before and after the test. Again, from the Archard's wear law [32], the specific disc wear rate was determined as

$k_{d}=\frac{\Delta m}{\rho \cdot \Delta s \cdot F_{N}}$

where $\Delta m$ is the mass loss of the specimen and $\rho$ is the density of the specimen. An ELPI+ (Electrical Low Pressure Impactor) particle instrument was used to register the airborne mass concentration (PM10 particles with an aerodynamic diameter smaller than $10 \mu \mathrm{m}$ ) during testing at a sampling rate of $1 \mathrm{~Hz}$. The density of the particles measured is set to $1 \mathrm{~g} / \mathrm{cm}^{3}$. With the concentration known, the airborne mass rate $[\mu \mathrm{g} / \mathrm{m}]$ was calculated as $[10]$.

$n=\frac{1}{s} \int_{t_{1}}^{t_{2}} c \cdot Q \cdot d t$

where $c$ is the measured number or mass concentrations of the particles, $Q$ is the air flow rate through the chamber, $t_{1}$ and $t_{2}$ are the start time and end time of the period studied, and $s$ is the sliding distance between $t_{1}$ and $t_{2}$.

The nominal contact pressure $(p)$ and sliding velocity $(v)$ map of the specific wear rate of the pin is presented in Fig. 3. The nominal contact pressure and sliding velocity map for the airborne mass rate is presented in Fig. 4. Note that the specific wear rate for the pin is determined from real-time measurements using an LVDT displacement sensor which makes it possible to exclude the run-in period. The specific wear rate of the disc is set to $4 \cdot 4 \cdot 10^{-15} \mathrm{~m}^{3} / \mathrm{Nm}$, which is the mid value of the $p v$-map obtained weighting the disc before and after the test.

\section{FEA approach}

The first step of the simulation algorithm is to set up the FE-model to compute the contact pressure distribution during braking in order to be able to calculate the wear and the particle emissions. The model has been developed starting from the work of Valota et al. [17]. It has been expanded to consider the specific wear variation of the pads with sliding velocity and contact pressure, and to compute the particle emissions by introducing wear and particle emission $p v$-maps. The simulation procedure has been implemented in Abaqus [33]. A routine has been developed to compute the wear and the particle emissions for each braking of the load cycle test (see subsection 2.2). After each braking, the mesh is updated by removing the computed wear and the FEA is solved for the next braking. An overview of the simulation

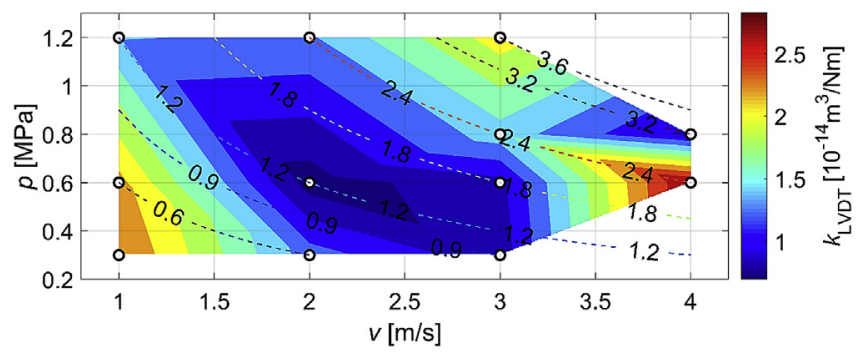

Fig. 3. Nominal contact pressure (p) and sliding velocity (v) map of the pin specific wear rate $\left(\mathrm{k}_{\mathrm{LVDT}}\right)$. The $\mathrm{p}$ and $\mathrm{v}$ used in the pin-on-disc tribometer are marked with circles. The pv-values are represented with dashed isolines. 


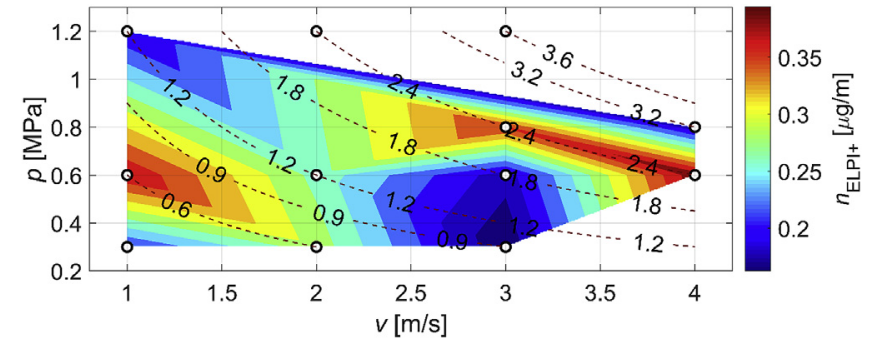

Fig. 4. Nominal contact pressure (p) and sliding velocity (v) map of the airborne mass rate $\left(\mathrm{n}_{\mathrm{ELPI}}+\right)_{\text {. The }} \mathrm{p}$ and $\mathrm{v}$ used in the pin-on-disc tribometer are marked with circles. The pv-values are represented with dashed isolines.

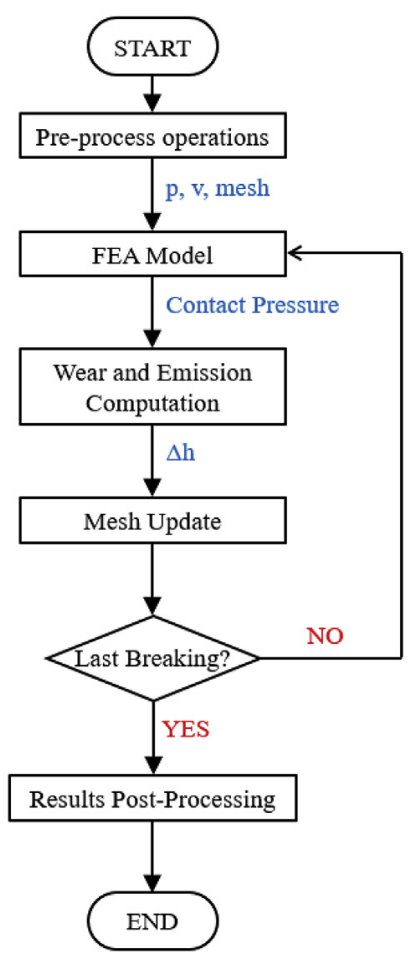

Fig. 5. FEA simulation routine.

algorithm is shown in Fig. 5. In the subsections following, the FE model setup, the wear, and particle emission routine will be explained.

\subsection{Pre-process}

The procedure starts with a pre-process in which the geometries are defined, the meshes are generated, and test cycle is set. The FE simulation includes the disc brake components: rotor, pads friction material, backplates, piston, calliper, carrier, and sliding pins. An illustration of the meshed components is given is shown in Fig. 6. The applied load and the rotational velocity are defined by the test cycle.

The calliper can slide with respect to the grounded carrier on the sliding pins. The load consists of two steps. First, the pressure is applied on the back of the piston and to the cylinder walls. Second, the pressure is kept and a motion is applied to the rotor to simulate the rotation.

The FEA output is the contact pressure distribution of the pads-disc interface during braking. To simplify the wear routine, the rotor and friction material mesh is set to be hexahedral and the angular distance between nodes $(\Delta \theta)$ on the brake ring is set to be constant. Abaqus ALE (Arbitrary Lagrangian Eulerian adaptive meshing) technique manages the nodes position update after every braking [34].

\subsection{Wear computation}

A subroutine has been developed in order to determine the wear and the particle emissions during a test cycle. The wear and the emissions are considered for both the pads and the rotor. The $p v$-map in Fig. 3 is used to compute the pad-specific wear rate as a function of the local contact pressure and the sliding velocity. The disc specific wear rate is set as constant. A generalization of Archard's wear law [32] is used to compute the amount of wear for every node. According to this law, for the pad nodes, the wear is given by the product between the specific wear rate, the contact pressure, and the sliding distance:

$\Delta h_{p}=k_{p}(p, v) \cdot p \cdot \Delta s$

where $k_{p}$ is the specific wear rate of the pad, and it is a function of pressure and velocity, $p$ is the cell contact pressure that is kept constant during every braking, and $\Delta s$ is the node sliding distance. To take the speed change during a braking into account, every braking is divided into $n$ steps and Eq. (4) is computed $n$ times for every braking. The deceleration $a$ is considered constant during a single braking. Considering the time discretisation of each brake event, the pad wear during a single braking can be re-written as follows:

$\Delta h_{p}=p \sum_{i=1}^{n} k_{p}\left(p, \frac{v_{i}+v_{i+1}}{2}\right) \Delta s_{i}$

where $\Delta s_{\mathrm{i}}$ is the sliding distance during a sub-step and, considering the constant deceleration $a$, it can be computed using the linear motion equation by Eq. (6):

$\Delta s_{i}=v_{i} \Delta t+\frac{1}{2} a \Delta t^{2}$

Assuming a constant deceleration during a braking, the disc wear can be computed as follows [17]:

$\Delta h_{d}=\frac{\alpha}{2 \pi} \sum_{\theta=0}^{2 \pi} k_{d} \frac{p(r, \theta)+p(r, \theta+\Delta \theta)}{2} \Delta \theta r$

where $\alpha$ is the rotation angle and $k_{d}$ is the disc specific wear rate. Note that a point on the disc is only worn when it passes the contact.

\subsection{Particle emission computation}

In the same way as for the pad wear, a $p v$-map used as input for the particle emission computation (Fig. 4). From this map, knowing the node contact pressure and the sliding velocity, the particle emissions are given as mass per sliding distance $[\mu \mathrm{g} / \mathrm{m}]$. Starting from the map it is possible to compute the total brake emissions for each brake event.
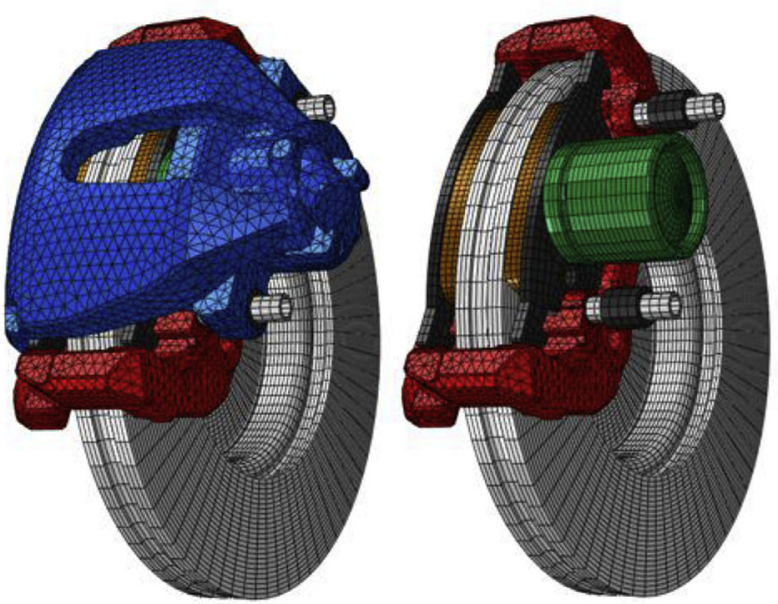

Fig. 6. Mesh of the simulated geometry. 
The brake emission for each braking, in terms of mass, is given by the map in Fig. 4 scaling the nodal area with the pin area and considering the sampling efficiencies:

$m_{\text {particles }}=\eta_{P O D} n_{E L P I+}(p, v) \frac{A_{\text {nodal }}}{A_{\text {pin }}}$

where $n_{\mathrm{ELPI}}+$ is the particle emission per sliding distance and is given by the $p v$-map, $A_{\text {nodal }}$ is the nodal area of the FEA mesh, $A_{\text {pin }}$ is the pin area, and $\eta_{\mathrm{POD}}$ is the particle sampling efficiency of the pin-on-disc tribometer due to anisokinetic sampling. This sampling efficiency has been simulated with a CFD (Computational Fluid Dynamics) analysis by Riva et al. [35] to $80.1 \%$ for PM10 emissions and considers the sampling losses due to anisokinetic conditions in the tribometer test setup.

Considering that in every braking the contact pressure and the deceleration are constant, only the velocity changes. To consider this velocity change, as done for the pad wear computation, every braking can be time-discretised in $n$ sub-steps, and Eq. (8) can be re-written as follows:

$m_{\text {particles }}=\eta_{P O D}\left(\sum_{i=1}^{n} n_{E L P I+}(p, v) \Delta s_{i}\right) \frac{A_{\text {nodal }}}{A_{\text {pin }}}$

where $\Delta s_{i}$ can be determined by Eq. (6).

\section{Dyno bench test}

An inertia dyno bench designed for studies of airborne emissions from disc brakes [11] is used in the present work to investigate the validity of the simulation. The test bench is schematically described in Fig. 7. In this dyno bench setup, the brake system is mounted inside a clean chamber. The air is taken from inside the laboratory, passes through a HEPA (High Efficiency Particulate Air) filter and goes inside the inlet pipe and finishes inside the chamber. The air inlet velocity is $5 \mathrm{~m} / \mathrm{s}$, which corresponds to a flow of $850 \mathrm{~m}^{3} / \mathrm{h}$, allowing a chamber air exchange rate of $0.236 / \mathrm{s}$. Near to the chamber entrance, two walls are introduced to avoid the inlet flow direct hitting the brake system. The air and the particles are mixed in the chamber due to the turbulent flow inside the chamber. A sampling pipe guarantees isokinetic conditions at the measurement point. In this test, the isokinetic velocity was $3.47 \mathrm{~m} /$ s. The same kind of particle counter used in the pin-on-disc tribometer setup (DEKATI ELPI+) was used to monitor particle emissions at the sampling point of the dyno bench. The sampling rate of $1 \mathrm{~Hz}$ was used in both the setups. The density of the measured particles was set to $1 \mathrm{~g} /$ $\mathrm{cm}^{3}$. The pads and rotor are weighted before and after the tests to determine their loss of mass with the Sartorius balance MSE14202S (repeatability $\pm 0.01 g$ ).

\section{Results}

The result section is divided into two parts. The outputs of the wear simulation are presented in the first section while the outputs of the emission simulation are presented in the second part.

\subsection{Wear}

The contact pressure distribution for two similar brake events, in terms of pressure in the cylinder of the calliper $\left(p_{\text {cyl }}\right)$, at the beginning and at the end of the LACT cycle are shown in Fig. 8 in order to illustrate the development of the contact pressure. The two brake events correspond to brake event \#2, $p_{\text {cyl }}=0.42 \mathrm{MPa}$, and brake event \#195, $p_{\text {cyl }}=0.4 \mathrm{MPa}$. The piston side pad contact pressure distributions (Fig. 8: left column) shows that the pressure increases with the radii and toward the disc inner side at the beginning of the test; at the end of the cycle the contact pressure is more uniform. On the finger side (Fig. 8: right column), the contact pressure increases just with the radii at the beginning of the cycle and it has a gradient from the centre to the inner and outer sides at the end of the cycle. It can be also noted that the only border that works a lot during braking is the outer side of the pistons pad, where high pressure values are shown.

The pad wear after the brake event \#2 and \#195 is shown in Fig. 9. After brake event \#2 the wear is close to zero. After brake event \#195, at the end of the cycle, the pad wear is generally higher for larger radii. Moreover, the wear gradient is moved slightly towards the inner side for the piston side pad.

The disc wear is presented in Fig. 10. As for the pads, two brake events are not enough to see a significant wear of the disc contact surfaces. The disc has a uniform wear that is higher on the finger side at the end of the cycle. Moreover, the outer radii present a higher wear on both sides of the disc.

In Fig. 11, the pads and disc cumulative mass loss during the whole test cycle (left column) and for each brake event (right column) are shown. The worst brake event in terms of wear is \#65, from $154 \mathrm{kph}$ to $36 \mathrm{kph}$ with a deceleration of $0.5 \mathrm{~m} / \mathrm{s}^{2}$ and an initial temperature of $90{ }^{\circ} \mathrm{C}$. This is also the brake event with the longest sliding distance.

Table 4 shows the measured total pads and rotor mass lost after five reduced LACT cycles. The simulation results are multiplied by a factor of five to obtain a value comparable with the experimental tests. The results show that the pad wear is slightly overestimated, while disc one is slightly underestimated by the simulation. The percentage error is $19 \%$ for both pads and disc. The total amount of wear of all the components results with a percentage error of $1 \%$.

\subsection{Particle emissions}

The measured PM10 emissions for each brake event during the reduced LACT cycle are shown in Figs. 12 and 13 for brake events \#1-109 and \#110-217, respectively. The first row of every picture represents the experimental results as the mean of the five reduced LACT cycles run with its standard deviations marked. The second row represents the results of the simulation.

In Table 5 a comparison between the measured and simulated total PM10 emissions is presented. The simulated PM10 emissions are inside the measured standard deviation, except for the group of braking 56-109, which has a simulated value slightly outside.

\section{Discussion}

The aims of simulations are to explain physical phenomena which happen during experiments and/or in the field, and to predict how a novel design will work during usage. A simulation tool that can provide a prediction of wear and airborne emissions from disc brakes could be a

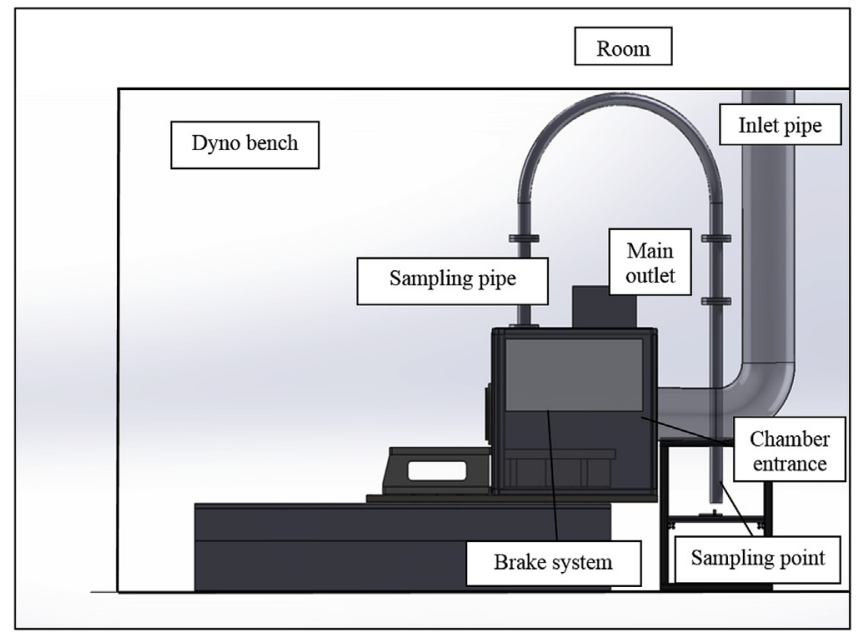

Fig. 7. A schematic overview of the inertia brake dyno bench setup designed for emission measurements [11]. 


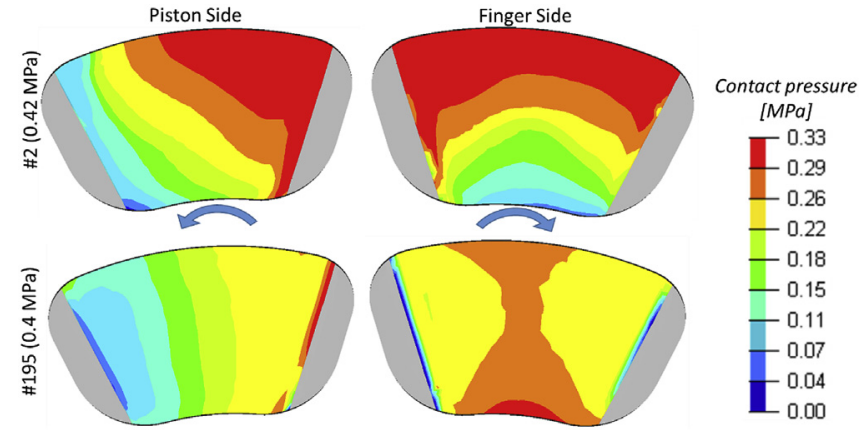

Fig. 8. Contact pressure distribution on the piston (left column) and finger (right column) side. Row 1: brake event \#2 ( $\left.\mathrm{p}_{\text {cyl }}=0.42 \mathrm{MPa}\right)$. Row 2: brake event \#195 $\left(\mathrm{p}_{\mathrm{cyl}}=0.4 \mathrm{MPa}\right)$. The arrow marks the rotational direction of the rotor.

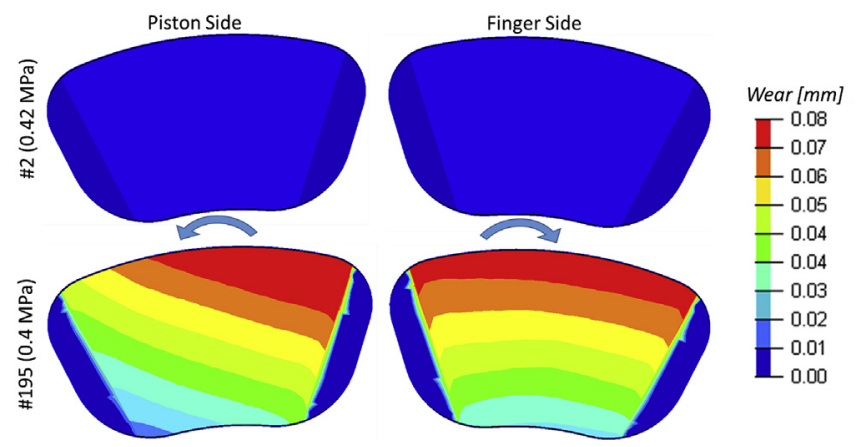

Fig. 9. Pad wear on the piston (left column) and finger (right column) side. Row 1: brake event \#2 ( $\left.p_{c y l}=0.42 \mathrm{MPa}\right)$. Row 2: brake event \#195 $\left(p_{c y l}=0.4 \mathrm{MPa}\right)$. The arrow marks the rotational direction of the rotor.

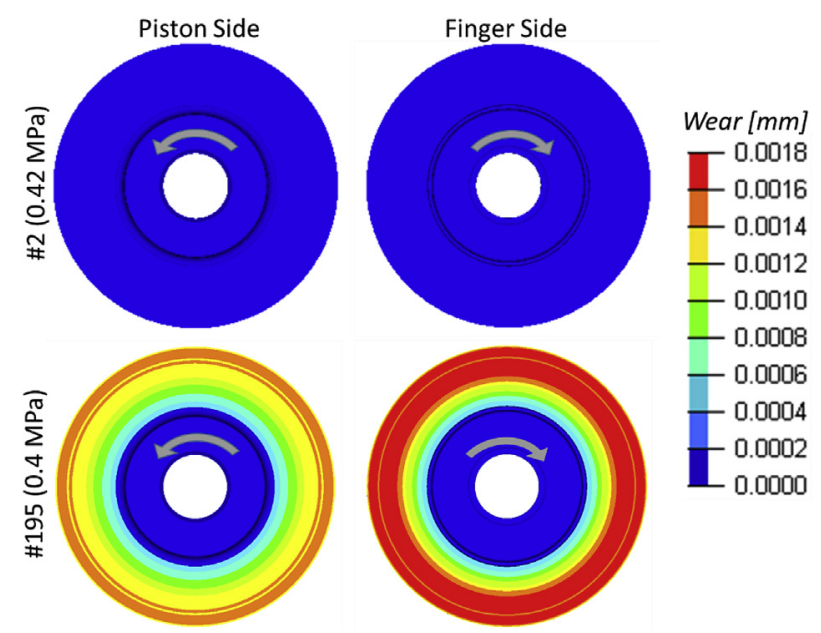

Fig. 10. Rotor wear on the piston (left column) and finger (right column) side. Row 1: brake event \#2 ( $\left.\mathrm{p}_{\mathrm{cyl}}=0.42 \mathrm{MPa}\right)$. Row 2: brake event \#195 $\left(\mathrm{p}_{\mathrm{cyl}}=0.4 \mathrm{MPa}\right)$. The arrow marks the rotational direction of the rotor.

crucial tool in the design phase of novel disc brake systems. In the present work, the validity of an FEA simulation approach to predict wear and airborne emissions was investigated.

Two of the main factors influencing the wear are the contact pressure and sliding distance. By comparing brake event \#2 and \#195, it is possible to see how the wear of the pads (Fig. 9) and rotor (Fig. 10) adapt their contact surfaces to even out the contact pressure distributions (Fig. 8). This is a consequence of the Archard's wear law. Also, it is possible to see that the wear increases with the sliding distance for both the pads and the rotor. This is clearer on the rotor surface since there is no wear gradient in the tangential direction due to the rotation. In contrary, the pad wear is influenced by the contact pressure and the sliding velocity in a tangential direction. It is important to remember that the pad wear dependence on the contact pressure and sliding velocity is non-linear since it also depends on the specific wear of the pad, which depends on these two variables.

Temperature effects are neglected in the presented simulation approach. It is known that the temperature of disc brake systems influences both the material and system parameters for the pads and rotor. Thermal expansion or softening of the materials could affect the contact pressure distribution and contact area, and in turn, the local wear. Also, it is known that the resin of the pad materials is sensitive to high temperatures. Cristol-Bulthé et al. [36] tested an OMC pin against a cast iron disc with a pin-on-disc tribometer at different controlled disc temperatures, and concluded that the wear depth of the pad resin is about $35-55 \mu \mathrm{m}$ at disc temperatures below $100^{\circ}$ and $50-75 \mu \mathrm{m}$ at disc temperatures above $500{ }^{\circ} \mathrm{C}$. This could also affect the contact pressure and area distribution. It should be mentioned that, as regards wear and emissions, the dependence of temperature is implicitly given by the $p v$ maps, since a higher $p v$ will result in a higher temperature.

In the present work, the mass of airborne particulate matter is considered and not the number of particles. It is known that the generation of ultrafine airborne particles is strongly affected by the pad temperature (e.g. Refs. [10,37,38]). At a disc temperature about $170-190{ }^{\circ} \mathrm{C}$, which corresponds to a $p v$-value around $1.4-1.8 \mathrm{MPa} \mathrm{m} / \mathrm{s}$ depending on pad friction material, the number of ultrafine particles can increase by several factors ([10,37]). These kinds of temperatures are not reached with the urban test cycle used. It is possible to include this in the simulation in the future by using a $p v$-map for the particle number rate. It should be noted that the repeatability of experiments focussing on measurements of ultrafine particles from disc brakes is low [10].

To better understand the differences in simulated and measured wear two points are discussed below. First, the load is determined by the brake torque to obtain a constant deceleration in the inertia dyno test while in the FEA the cylinder pressure and coefficient of friction are set as constant. This results in a constant brake torque during a brake event. Second, the weight of the pads and rotor was measured before and after five reduced LACT cycles. The first reduced cycles could still be in the run-in phase. On the other hand, the simulation corresponds to a single reduced LACT cycle, with the geometry corresponding to the new configuration.

There are few studies reported in the literature about the simulation of airborne emissions from disc brakes. Wahlström et al. [18] presented an FEA approach and used it to simulate wear and airborne emissions from a disc brake contact pair run at constant normal load and rotational velocity. The images presented of the simulated wear are different from the result presented in the present paper. This could be explained by the fact that they did not include the effect of the calliper in the FEA. By including the calliper, it is possible to consider nonsymmetric effects between the piston and finger side. The contact pressure acting on the finger side pad is not the same as the piston side pad since the load is applied in a different way (see Fig. 2). Moreover, the brake torque pushes the backplates of the pads against the calliper supports which results in a non-symmetric pressure distribution in the tangential direction. Also, the reduced LACT cycle used in the present work is made by continuously changing brake torque and rotational velocity, because it represents a city traffic cycle. With this kind of cycle, no steady state condition is reached in the end, and no uniform contact pressure distribution is reached. The specific wear rate and contact pressure are not constant due to the continuous change in the kind of brake event. Sliding distance, instead, is always higher on external radii, which is why it appears clear for both pads and rotor that the higher the radius, the higher the wear is. The same considerations can be made when looking at the work of Söderberg et al. [16], where the influence of the pistons is more evident on the wear. 


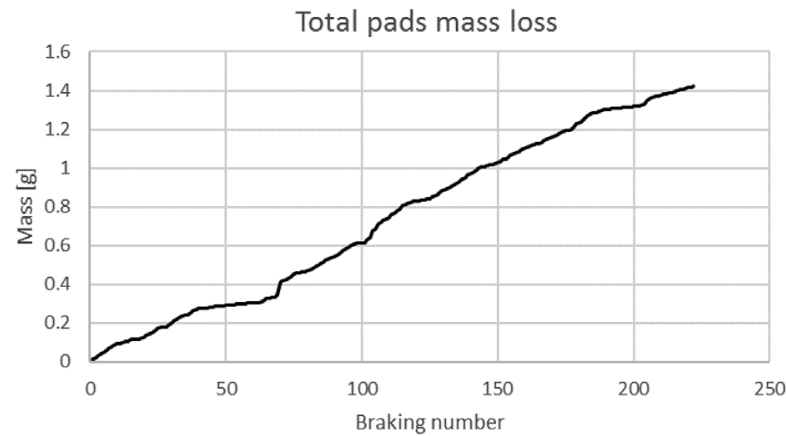

Total disc mass loss

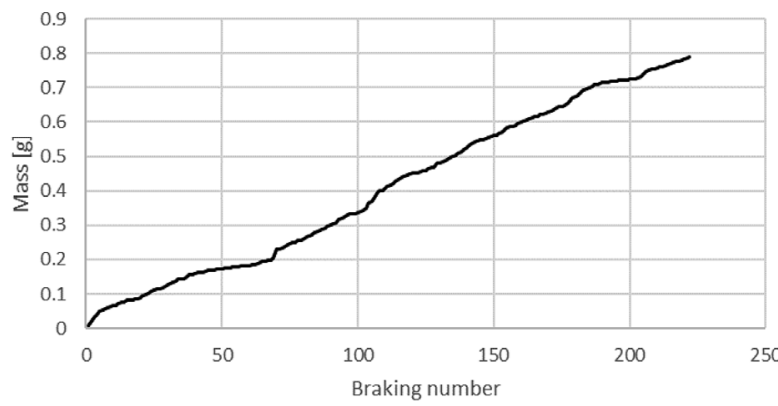

Pads mass loss

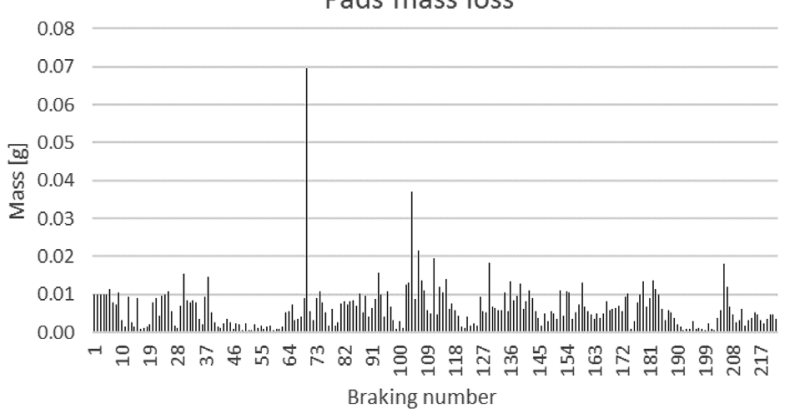

Disc mass loss

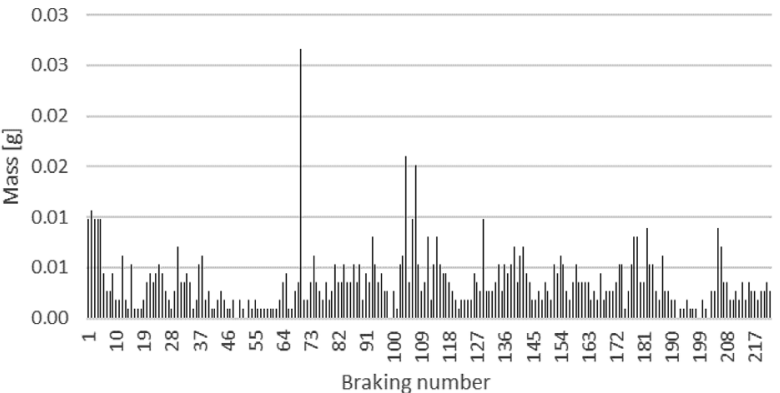

Fig. 11. Simulated mass loss for the pads and rotor during one reduced LACT. Left column: cumulative mass loss. Right column: mass loss per each individual brake event.

Table 4

Measured and simulated mass losses after five reduced LACT tests.

\begin{tabular}{llll}
\hline & Measured mass loss $[g]$ & Simulated mass loss $[g]$ & Percentage error [\%] \\
\hline Pads & 5.96 & 7.11 & $19 \%$ \\
Rotor & 4.90 & 3.94 & $-19 \%$ \\
Total & 10.86 & 11.05 & $1 \%$ \\
\hline
\end{tabular}

Valota et al. [17] showed the results of a FEA using a fixed calliper tested with the SAE-J2707 wear cycle. This cycle is divided into blocks of equal deceleration braking. In this way, a situation closer to the steady condition seems to be reached and the disc wear is uniform along the braking ring where the pads slide. Also, the pad wear is more uniform, but is more concentrated in the upper half of the contact area. It is important to underline that these results were obtained considering a fixed calliper, so the pressure distribution can be completely different because the braking mechanism is different. Abubakar et al. [24] used an FEA approach to simulate the contact pressure distribution during

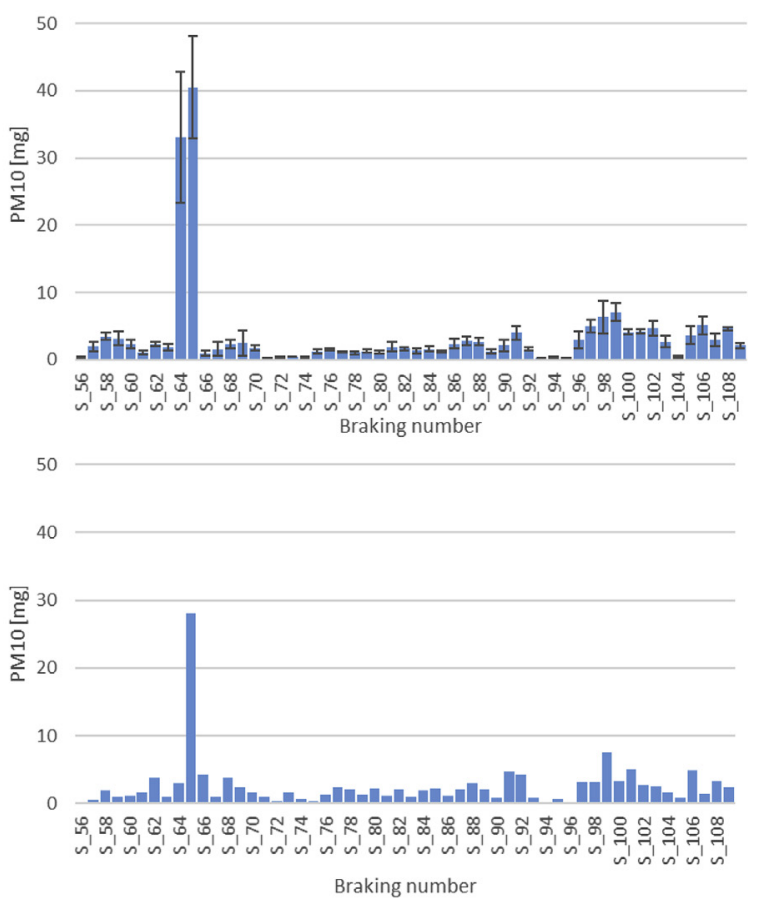

Fig. 12. Measured (upper row) and simulated (lower row) PM10 emission for brake event 1-100. 

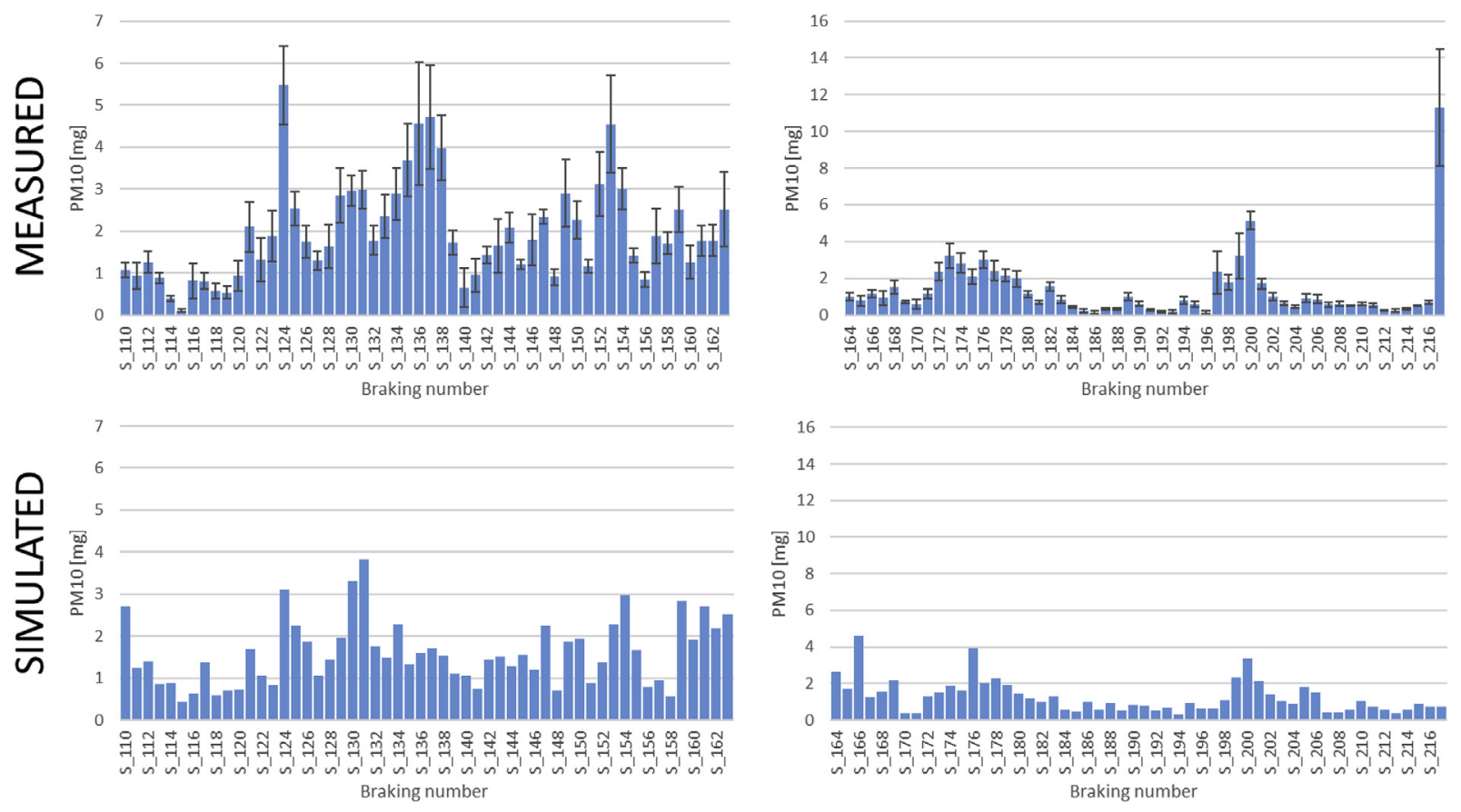

Fig. 13. Measured (upper row) and simulated (lower row) PM10 emission for brake event 101-196.

Table 5

Measured and simulated airborne PM10 emission.

\begin{tabular}{llll}
\hline Brake event [\#] & $\begin{array}{l}\text { Measured PM10 } \\
{[\mathrm{mg}]}\end{array}$ & $\begin{array}{l}\text { Simulated PM10 } \\
{[\mathrm{mg}]}\end{array}$ & $\begin{array}{l}\text { Relative error } \\
{[-]}\end{array}$ \\
\hline $1-55$ & $74 \pm 17$ & 77 & $4 \%$ \\
$56-109$ & $190 \pm 47$ & 139 & $-27 \%$ \\
$110-163$ & $106 \pm 25$ & 86 & $-18 \%$ \\
$164-217$ & $72 \pm 16$ & 68 & $-6 \%$ \\
$1-217$ (total) & $442 \pm 105$ & 370 & $-16 \%$ \\
\hline
\end{tabular}

80 min of dragging at constant pressure and rotational velocity. A floating calliper like the one used in this work has been employed. At the beginning of the cycle they found higher pressure values at higher radii, while after $80 \mathrm{~min}$ the contact pressure is more uniform on the entire surface, which is higher where the contact pressure and the sliding distance are greater. This behaviour is in line with what has been presented in this work, especially for the pad on the finger side (Fig. 8: left).

One way to investigate and validate a simulation model is to compare experimental and simulation results. The focus of the driving cycle used in the present work was to simulate city driving. To simulate the total wear and airborne emissions during the lifetime of a brake system, different test cycles which consider different driving styles and traffic situations could be run.

\section{Conclusions}

An FEA simulation approach has been further developed to simulate the wear and airborne emissions from a full disc brake. This was done by introducing $p v$-maps for local pad specific wear rates and airborne PM emissions obtained from pin-on-disc tribometer tests. The simulation results have been compared with an experimental test conducted with an inertia dyno bench adapted for airborne particle emission measurements. An urban driving cycle, a reduced LACT, was used in the simulations and measurements. According to the comparison, it can be concluded the simulated and the measured results are in line. The percentage error of the simulated wear is $19 \%$ for both pads and rotor. The pads wear is underestimated while the rotor wear is overestimated.
The simulated PM10 emissions are in general within the standard deviation of the measured emissions. Based on this, the proposed methodology seems promising to simulate wear and particle emissions from a disc brake system during city driving conditions. Further studies are needed to investigate the run-in influence in the computation of the specific wear rate and to investigate the wear and emission sensitivity to the number of reduced LACT cycles.

\section{Acknowledgements}

The research leading to these results received funding from the European Union's Horizon 2020 research and innovation programme under grant agreement No. 636592 (LOWBRASYS project).

\section{References}

[1] OECD. Health at glance 2017: OECD indicators [internet]. OECD Publishing; 2017 $210 \mathrm{p}$.

[2] GBD 2015 Risk Factor mental and occupational, and metabolic risks or clusters of risks 1990-2015: a systematic analysis for the Global Burden of Disease Study 2015.rs Collaborators. Global, regional, and national comparative risk assessment of 79 behavioural (London, England) [Internet]. Enviro Lancet

2016;388(10053):1659-724. EEA, "The European environment - state and outlook 2010, 2011".

[3] Straif K, Cohen A, Samet J, editors. Air Pollution and Cancer, IARC Scientific Publication No. 161. 2013.

[4] Amato F, editor. Non-exhaust emissions: an urban air quality problem for public health. San Diego: Academic Press ELSEVIER; 2018. p. 342.

[5] Grigoratos T, Martini G. Brake wear particle emissions: a review. Environ Sci Pollut Res 2015;22:2491-504.

[6] Tirovic M, Day AJ. Disc brake interface pressure distributions. Proc Inst Mech Eng Part D J Automob Eng 1991;205(2):137-46.

[7] Garg B, Cadle S, Mulawa P, Groblicki P. Brake wear particulate matter emissions. Environ Sci Technol 2000;34:4463-9.

[8] Kukutschová J, Moravec P, Tomášek V, Matějka V, Smolík J, Schwarz J, Seidlerová J, Šafářová K, Filip P. On airborne nano/micro-sized wear particles released from low-metallic automotive brakes. Environ Pollut 2011;159:998-1006.

[9] Sanders P, Xu N, Dalka T, Maricq M. Airborne brake wear debris: size distributions, composition, and a comparison of dynamometer and vehicle tests. Environ Sci Technol 2003;37:4060-9.

[10] Wahlström J, Matějka V, Lyu Y, Söderberg A. Contact pressure and sliding velocity maps of the friction, wear and emission from a low-metallic/cast-iron disc brake contact pair. Tribol Ind 2017;39(4):460-70.

[11] Perricone G, Wahlström J, Olofsson U. Towards a test stand for standardized measurements of the brake emissions. Proc Inst Mech Eng - Part D J Automob Eng 2016;230(11):1521-8. 
[12] Mathissen M, Grochowicz J, Schmidt C, Vogt R, Farwick zum Hagen FH, Grabiec T, Steven H, Grigoratos T. A novel real-world braking cycle for studying brake wear particle emissions. Wear 2018;414-415:219-26.

[13] Eriksson M, Lord J, Jacobson S. Wear and contact conditions of brake pads: dynamical in situ studies of pad on glass. Wear 2001;249:272-8.

[14] Gramstadt S. Methoden der in-situ Visualisierung der Reibzonendynamik trockenlaufender Reibpaarungen unter Ergänzung physikalischer und chemischer Charakterisierungen der Reibpartner Doctoral thesis Ilmenau, Germany: Universitätsverlag Ilmenau978-3-86360-107-2; 2015

[15] Afzal A, Mujeebu A. Thermo-mechanical and structural performances of automobile disc brakes: a review of numerical and experimental studies. M Arch Computat Methods Eng 2018:1-15.

[16] Söderberg A, Sellgren U, Andersson S. Using finite element analysis to predict the brake pressure needed for the effective rotor cleaning in disc brakes. SAE Int 200801-2565.

[17] Valota G, De Luca S, Söderberg A. Using a finite element analysis to simulate the wear in disc brakes during a dyno bench test cycle. Eurobrake 2017. EB2017-SVM003.

[18] Wahlström J, Söderberg A, Olofsson U. Simulation of airborne wear particles from disc brakes. SAE Technical Paper 2009-01-3040.

[19] Wahlström J. A comparison of measured and simulated friction, wear, and particle emission of disc brakes. Tribol Int 2015;92:503-11.

[20] Ostermeyer GP, Merlis JH. Modeling the friction boundary layer of an entire brake pad with an abstract cellular automaton. Lubricants May 2018;6:44.

[21] Müller M, Ostermeyer GP. A cellular automaton model to describe the three-dimensional friction and wear mechanism of brake systems. Wear 2007:263(7-12):1175-88.

[22] Wahlström J, Söderberg A, Olofsson U. A cellular automaton approach to simulate the contact situation between the pad and disc in disc brakes. Tribol Lett 2011;42:253-62.

[23] Riva G, Perricone G, Wahlström J. Simulation of contact area and pressure dependence of initial surface roughness for cermet-coated discs used in disc brakes. Tribology in Industry; 2019https://doi.org/10.24874/ti.2019.41.01.01.

[24] AbuBakar AR, Ouyangb H. Wear prediction of friction material and brake squeal using the finite element method. Wear 2008;264:1069-76.
[25] Han J, Lee CH, Park TW, Park JM, Son SM. Coupled thermo-mechanical analysis and shape optimization for reducing uneven wear of brake pads myeong. Int J Automot Technol 2017;18(6):1027-35.

[26] Goo BC. A study on the contact pressure and thermo-elastic behavior of a brake disc-pad by infrared images and finite element analysis. Appl Sci 2018;8:1639.

[27] Schmidt AA, Schmidt T, Grabherr O, Bartel D. Transient wear simulation based on three-dimensional finite element analysis for a dry running tilted shaft-bushing bearing. Wear 2018;408-409:171-9.

[28] Sun Y, Guo Y, Zhai W. Prediction of rail non-uniform wear - influence of track random irregularity. Wear 2019;420-421:235-44.

[29] Grigoratos T, Martini G. Development of a test cycle for the investigation of brake wear particles. Presented at the 41st PMP - particle measurement program UNECE informal group - non-exhaust traffic related particle emissions - 13 October 2016 meeting.

[30] Mody P, Rumold W, Attia F, Ansmann S. Mojacar. Los Angeles city traffic vehicle testing: a comparison and analysis of subjective ratings and objective measurements. Technical Paper 2002-01-2600, SAE Brake. 2002https://doi.org/10.4271/ 2002-01-2600.

[31] Mathissen M, Evans C. Lowbrasys brake wear cycle - 3h LACT. Mendeley Data; 2019https://doi.org/10.17632/4cgs6myx9d.1.

[32] Archard JF. Contact and rubbing of flat surfaces. J Appl Phys 1953;24:981-8.

[33] Information about Abaqus available at: https://www.3ds.com/products-services/ simulia/products/abaqus/.

[34] Information of Abaqus ALE technique available at: http://abaqus.software.polimi. it/v6.14/books/usi/default.htm?startat = pt03ch14s06.html.

[35] Riva G, Wahlström J, Alemani M, Olofsson U. A CFD study of a pin-on-disc trib ometer setup focusing on airborne particle sampling efficiency. Ecotrib 2017.

[36] Cristol-Bulthé AL, Desplanques Y, Degallaix G, Berthier Y. Mechanical and chemical investigation of the temperature influence on the tribological mechanisms occurring in OMC/cast iron friction contact. Wear 2008;264:815-25.

[37] Alemani M, Wahlström J, Olofsson U. On the influence of car brake system parameters on particulate matter emissions. Wear 2018;396:67-74.

[38] Kukutschová J, Moravec P, Tomášek V, Matějka V, Smolík J, Schwarz J, Seidlerová J, Šafářová K, Filip P. On airborne nano/micro-sized wear particles released from low-metallic automotive brakes. Environ Pollut 2011;159:998-1006. 